\title{
GIỚI THIỆU ÚNG DỤNG THỬ NGHIẸM CÔNG NGHỆ UAV VÀ GIS TRONG VIỆC GIÁM SÁT VÀ QUẢN LÝ HẸ THỐNG ĐƯờNG BỜ CỦA SÔNG HỒNG VÀ SÔNG ĐUỐNG
}

\author{
PHAM MINH HẢl, LƯU HẢl ÂU, ĐÕ TH!̣ HOÀl \\ Viện Khoa học Đo đạc và Bản đồ
}

\section{Mở đầu}

Tình trạng sạt lở bờ sông không chỉ làm mất đất sản xuất mà còn gây lo lắng cho người dân trong vùng, nhất là những hộ dân sống gần bờ sông. Nguyên nhân của hiện tượng sạt lở bờ sông là do điều kiện địa hình, địa chất, địa mạo, điều kiện kinh tế xã hội như các xây dựng trái phép lấn chiếm luồng lạch, tôn cao nền quá mức của các hoạt động dịch vụ theo bờ sông, khai thác cát quá mức dưới lòng sông. Hiện nay, các phương pháp truyền thống quan trắc sự thay đổi đường bờ thường là đo đạc thực địa. Hạn chế của phương pháp này là giá thành cao, mất nhiều thời gian và đặc biệt không cập nhật được kịp thời yếu tố biến động đường bờ sông. Do đó, ứng dụng công nghệ máy bay không người lái (Unmanned Aerial Vehicles - UAV) và hệ thống GIS trong việc giám sát và quản lý hệ thống đường bờ sông có tính thực tiễn và kinh tế cao.

\section{2. Đối tượng và phương pháp nghiên cứu}

\section{1. Đối tượng thử nghiệm}

Khu vực lòng sông, bãi sông, quản lý vi phạm hành lang và biến động lòng sông, bãi sông thuộc phạm vi sông Hồng, sông Đuống đoạn qua các tỉnh Hà Nam, Nam Định, Hưng Yên, Thái Bình, Bắc Ninh với diện tích trên $400 \mathrm{~km}^{2}$.

\subsection{Phương pháp nghiên cứu}

Để thực hiện quan trắc hệ thống đê điều trải dài trên khu vực thử nghiệm, nhóm thực hiện đề xuất giải pháp ứng dụng công nghệ máy bay không người lái (UAV). Ảnh được chụp từ UAV với độ phân giải mặt đất $14 \mathrm{~cm}$ và được sử dụng để thành lập các bình đồ ảnh số tỷ lệ $1 / 10.000$ bao trùm các bãi bồi ven sông, khu vực hai bên bờ sông, hệ thống đê dọc hai bên bờ sông. Công tác xử lý và thành lập bình đồ ảnh được thực hiện trên phần mềm $\mathrm{Px} 4 \mathrm{D}$. Để phục vụ công tác quản lý giám sát hiện trạng sử dụng lòng sông, bãi sông, quản lý vi phạm hành lang đê điều được dễ dàng, trong quá trình chụp ảnh hiện trạng của lớp phủ bề mặt địa hình cũng được quay phim ghi lại dưới dạng các file video với chất lượng phim là 1080p (1920 x1080) với các tuyến bay được bố trí bay dọc theo tuyến đê, quay phim khu vực từ sông vào đến đê theo hướng song song với tuyến bay: 01 tuyến phía bờ trái và 01 tuyến phía bờ phải.

Nhóm thực hiện đã xây dựng các bản đồ chuyên đề như: bản đồ sạt lở bờ sông; bản đồ sử dụng lòng sông, bãi sông; bản đồ vi phạm hành lang bảo vệ đê; các sơ đồ thể hiện hiện trạng mặt đề, mái đê, chân đê trong khu vực khảo sát. Các bản đồ biến động đường bờ khi so sánh với thời điểm năm 2004 trên ảnh hàng không đã được thu thập. Các công trình, đối tượng thể hiện trên bản đồ bao gồm: đê, kè, cống, cửa khẩu qua đê; ao hồ, lòng sông; đường bờ sông; nhà; đường giao thông, cầu, cảng; bãi vật liệu .v.v... Cuối cùng, các sản phẩm bản đồ đã được thành lập sau đó được tích hợp vào cơ sở dữ liệu đê điều. (xem hình 1) 


\section{Kết quả phân tích} Hồng

3.1. Kết quả phân tích khu vực sông

Kết quả phân tích xác định dịch chuyển đường bờ sông - Sông Hồng đoạn từ Vạn Phúc đến cửa Luộc cho thấy giai đoạn từ năm 2004 đến nay, đường bờ trái về cơ bản không có biến động nhiều trừ một khu vực đường bờ dịch chuyển về phía bãi (xói bãi) gần 400m ở Đông Kết - Khoái Châu - Hưng Yên và một khu vực dịch ra phía sông (bồi bãi) khoảng 220m ở Hồng An - Kim Động Hưng Yên. Hiện tại, đường bờ trái về cơ bản thay đổi không nhiều trừ các khu vực: Đức Hợp, Đông Kết - Kim Động (xói bãi) và Hồng An - Kim Động (bồi bãi). Đường bờ phải biến động nhiều hơn nhưng chủ yếu là xu thế dịch chuyển ra sông (bồi bãi) khá lớn, chỉ có một khu vực đường bờ phải dịch chuyển mạnh vào bãi sông khoảng 400 ở Hàm Tử - Khoái Châu (Hưng Yên). (xem hình 2)
Kết quả phân tích xác định dịch chuyển đường bờ sông - Sông Hồng đoạn từ cửa Luộc đến cửa $B a$ Lạt cùng thời điểm quan trắc cho thấy đường bờ trái về cơ bản không có biến động nhiều trừ một khu vực đường bờ dịch chuyển về phía bãi (xói bãi) gần 180m ở Tân Hưng - Tiên Lữ (Hưng Yên) và một khu vực dịch ra phía sông (bồi bãi) khoảng 150m ở Bách Thuận- Vũ Thư (Thái Bình), các khu vực khác có biến động nhưng không đáng kể. (xem hình 3)

Nhìn chung tại khu vực sông Hồng, mặc dù quá trình biến động thay đổi qua các chu kỳ quan trắc, có thể thấy rằng đường bò̀ trái hiện tại về cơ bản thay đổi không nhiều, các khu vực biến động có mức độ không lớn, thường $<5 \mathrm{~m}$. Tuy nhiên, đường bờ phải biến động nhiều hơn nhưng chủ yếu là xu thế dịch chuyển ra sông (bồi bãi), xu thế dịch vào bãi khoảng 3-6m xuất hiện ở các khu vực gần cửa sông tại Giao Thiện, Giao Hương - Giao Thủy.

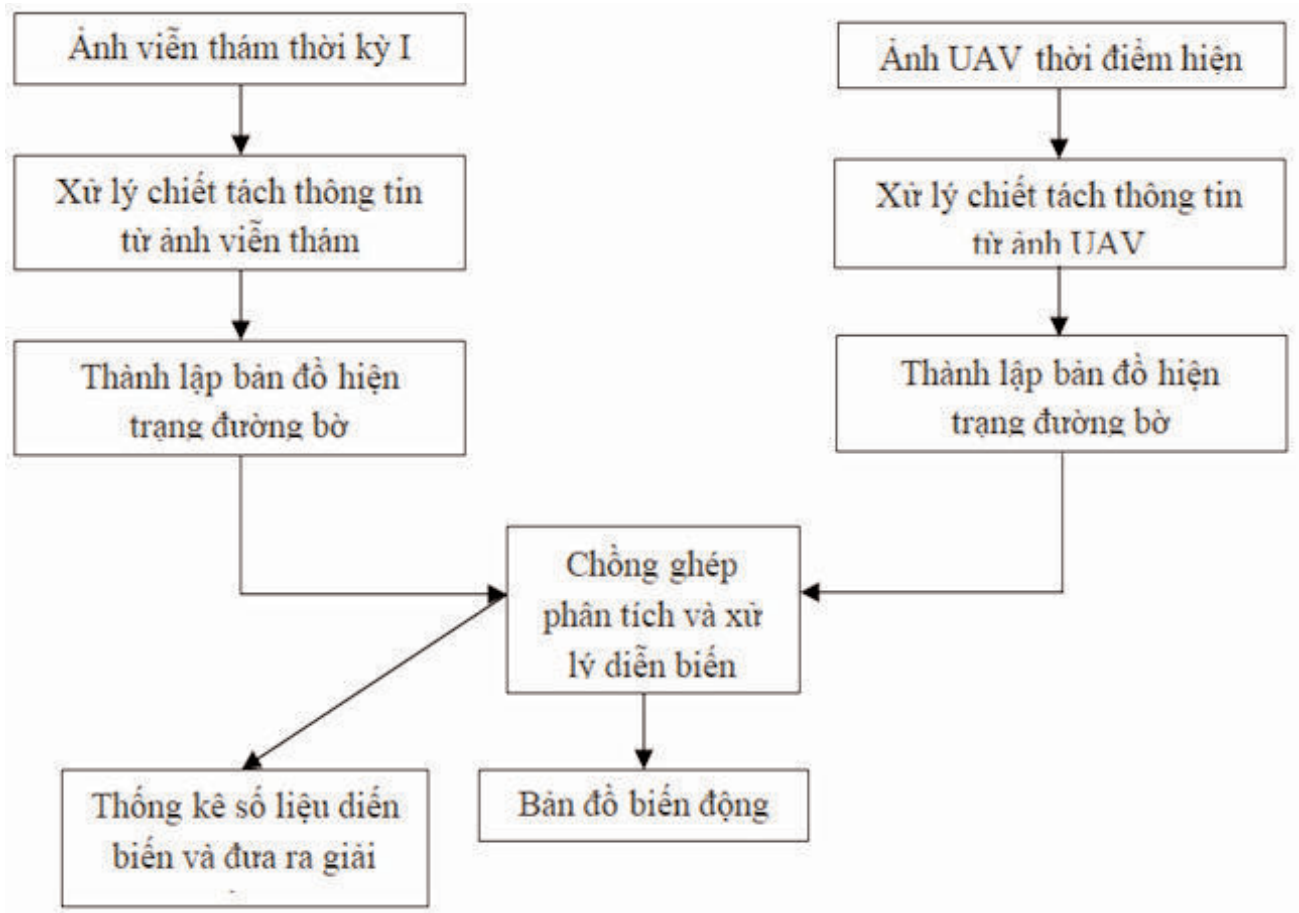

Hình 1: Quy trình thành lập bản đồ biến động đường bờ sông khu vực thử nghiệm bằng công nghệ UAV 


\subsection{Kết quả phân tích khu vực sông Đuống}

Từ năm 2004 đến nay, đoạn sông từ kè Kiều Lương đến kè Long Khê tương đối ổn định. Tuy nhiên, sau đó dòng chảy bắt đầu chuyển hướng tại khúc ngoặt gây hiện tượng sạt lở ở bờ trái giữa thời điểm năm 2014. Đoạn sông gần kè Long Khê phía bờ phải xảy ra hiện tượng sạt mạnh, lòng sông mở rộng từ $36 \mathrm{~m}$ lên đến $94 \mathrm{~m}$ ở đoạn sạt lở mạnh nhất, ăn sâu vào bờ, gần sát chân đê. (xem hình 4)
Đường bờ trái của Sông Đống có xu thế dịch chuyển về phía bãi (xói bãi) và phía sông (bồi bãi) xen kẽ nhau, tuy nhiên xu thế đường bờ dịch chuyển về phía bãi nhiều hơn, còn lại là đường bờ ổn định hoặc bồi nhẹ. Phía bờ phải, đường bờ tương đối ổn định, có xu thế dịch chuyển về phía bãi là chủ yếu nhưng mức độ dịch chuyển không lớn. Còn lại là những vị trí đường bờ ổn định hoặc dịch chuyển nhẹ ra phía sông nhưng mức độ không nhiều. (xem hình 5)

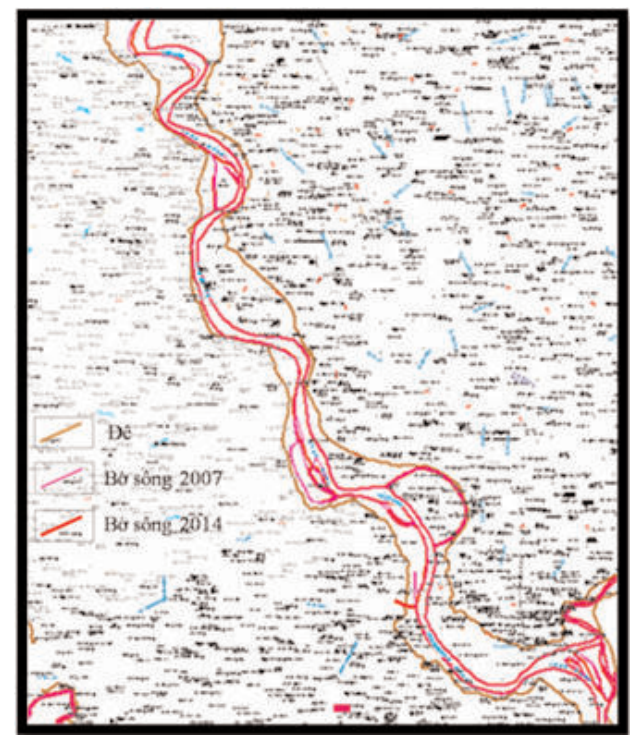

Hình 2: Kết quả phân tích xác định dịch chuyển đường bờ sông - sông Hồng đoạn từ Vạn Phúc đến cửa Luộc

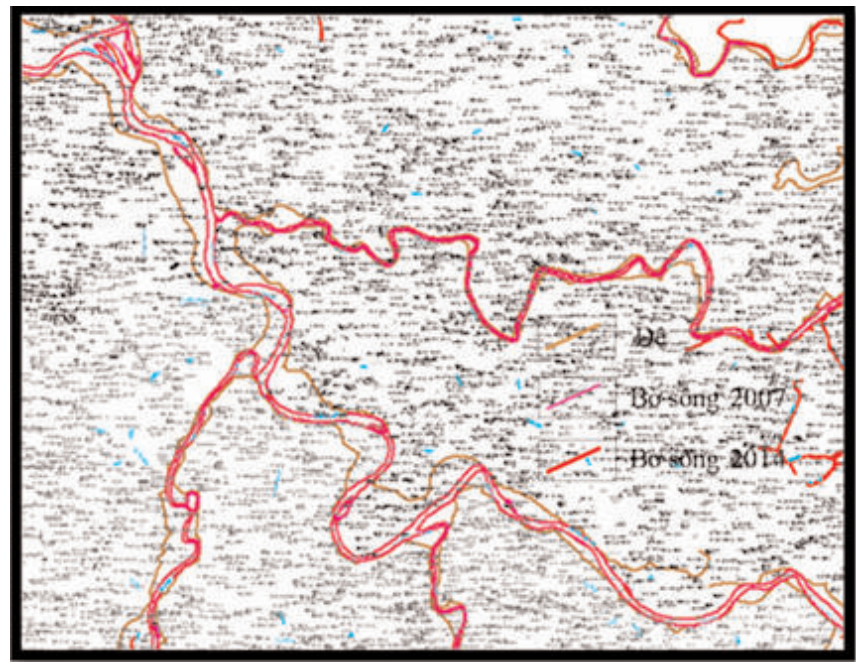

Hình 3: Kết quả phân tích xác định dịch chuyển đường bờ sông - sông Hồng đoạn từ Vạn Phúc đến cửa Ba Lạt

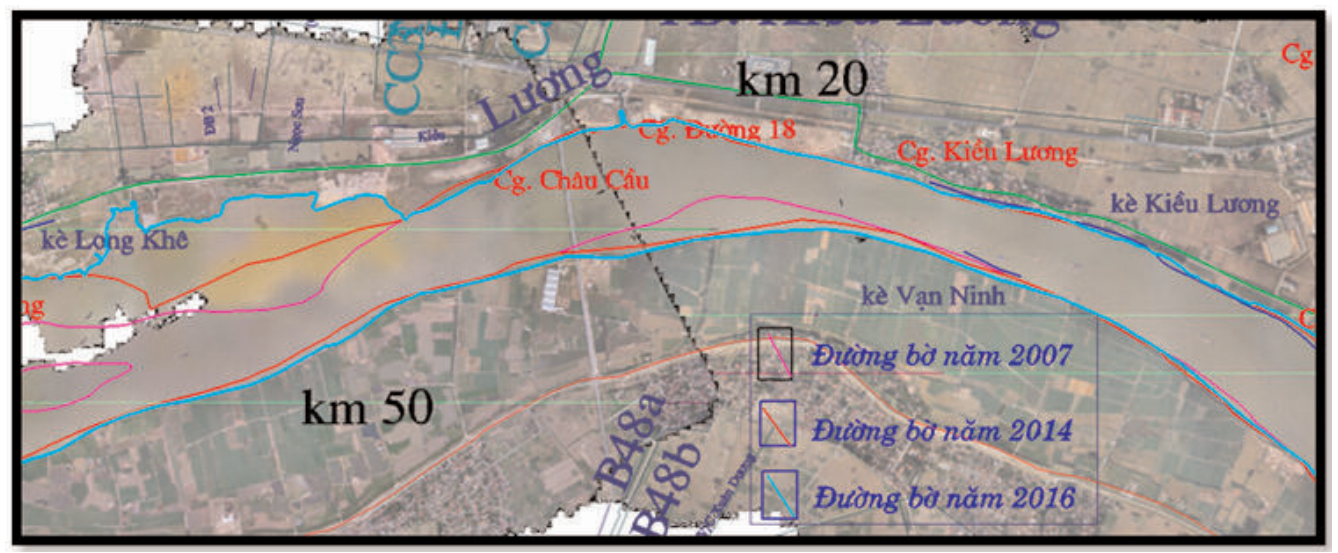

Hình 4: Biến động lòng sông Đuống đoạn từ kè Kiều Lương đến kè Long Khê 
Từ năm 2004 đến nay, đường bờ đoạn từ kè Cao Đức đến kè Vạn Ninh biến động nhiều chủ yếu phần kè Cao Đức do đoạn này nằm ở ngã ba sông Đuống, sông Phả Lại, sông Thái Bình, là nơi tập trung dòng chảy lớn. Tại đây, diện tích khu vực được trầm tích bồi đắp được tính toán vào khoảng $0.15 \mathrm{~m} / \mathrm{năm}$ trong giai đoạn này.(xem hình 6)

\section{Kết luận}

Các kết quả nghiên cứu đã cho thấy ứng dụng công nghệ máy bay không người lái (UAV), công nghệ định vị vệ tinh (GNSS) và công nghệ ảnh viễn thám trong thu thập dữ liệu để đánh giá nhanh hiện trạng đê điều đã cung cấp được nguồn số liệu đầy đủ phục vụ công tác quản lý, bảo vệ và duy tu đê điều. Với các khu vực có hệ thống sông lớn như tại đồng bằng Sông Hồng, nơi có hiện tượng xói lở bờ sông phức tạp, gây ra nhiều thiệt hại về tài sản và ảnh hưởng của người dân, cần nhân rộng việc sử dụng công nghệ viễn thám, đặc biệt là công nghệ máy bay không người lái trong xây dựng cơ sở dữ liệu để đánh giá hiện trạng và giám sát diễn biến đường bờ sông, dự báo xu hướng, sạt lở trong tương lai phục vụ hiệu quả công tác quản lý, cảnh báo sạt lở nói chung đảm bảo an sinh xã hội và phát triển kinh tế bền vững. $O$

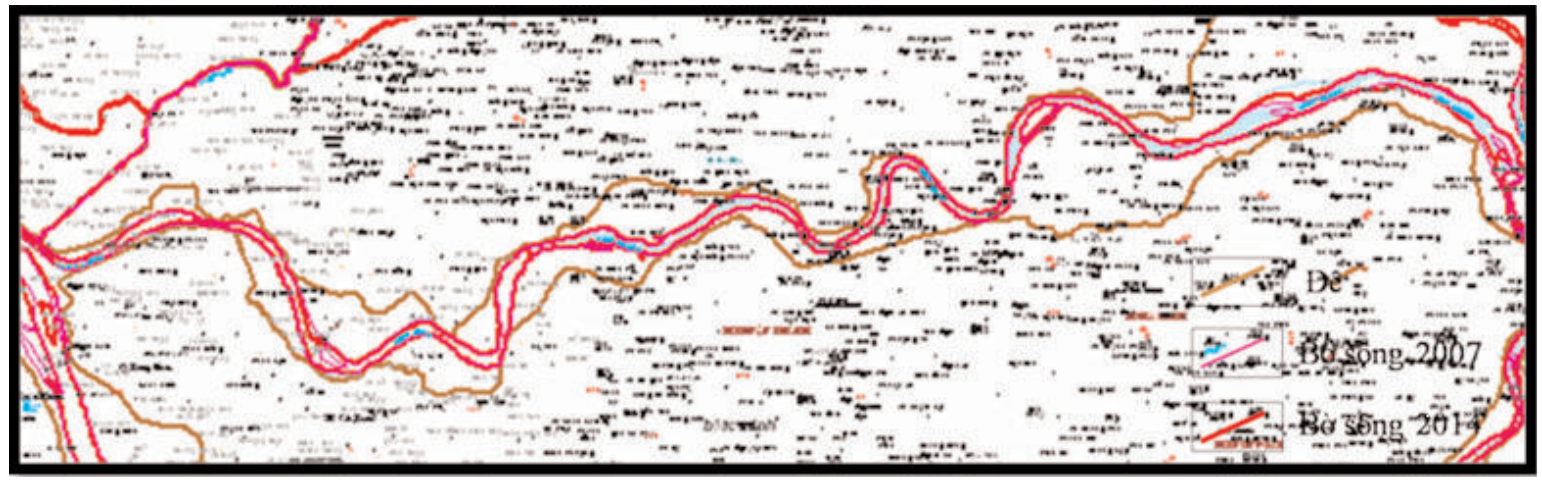

Hình 5: Kết quả phân tích xác định dịch chuyển đường bờ sông - sông Đuống từ Xuân Trạch - Đông Hội - Đông Anh - Hà Nội đến Phả Lại - Đức Long Quế Võ - Bắc Ninh

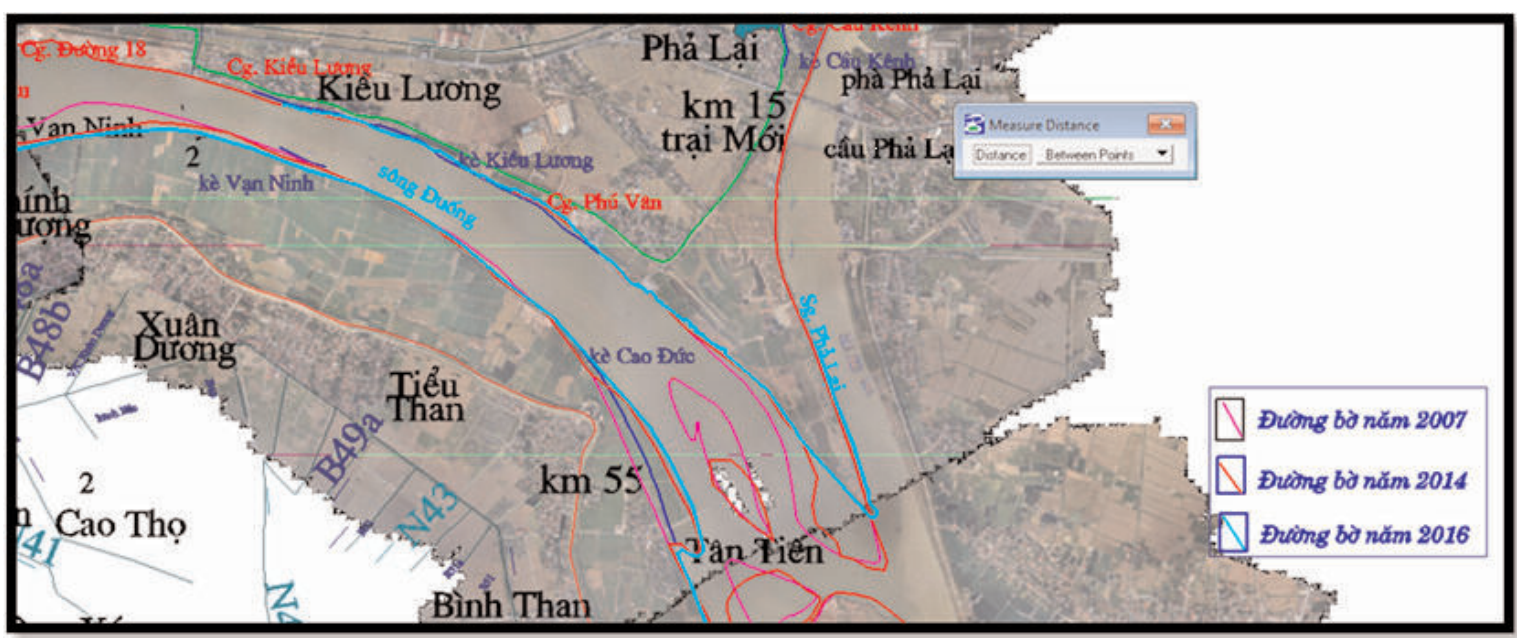

Hình 6: Đường bờ sông qua kè Cao Đức đến kè Vạn Ninh 